\title{
Epidemiology And Risk Factor Of Stroke In Babol, Northern Iran (2014-2015)
}

\author{
Alijan Ahmadi Ahangar ${ }^{1}$, Seyedeh Tahereh Taheri ${ }^{2}$, Shayan Alijanpour ${ }^{3 *}$ \\ ${ }^{1}$ Associated professor of Neurology, M obility Impairment Research Center, Babol University of M edical Sciences, \\ Babol, Iran \\ ${ }^{2}$ Nursing department. Ayatollah Rouhani hospital, Babol University of M edical Sciences, Babol, Iran \\ ${ }^{3}$ Emergency M edical Service Center, Babol university of medical science, Babol, Iran \\ *Corresponding Author: Email: Alijanpour.sh@live.com
}

Background: Stroke is the third leading cause of death worldwide. Data on the epidemiology of stroke, patterns and risk factors in recent years in our region are brief.

Methods and Material: This retrospective study from 2014 to 2015 on stroke patients was conducted. The NIHSS, the MRS and the Barthel index were used at admission and discharge. Patient's demographic data and checklist used to identify risk factor

Findings: A total of 230 stroke patients, 122 (53\%) was female. 194 patients (\%84) was ischemic type vs $36(\% 16)$ hemorrhagic, $\mathrm{P}<0001)$. Difference in risk factors was statistically significant (168 patients (\%73) had Hypertension, 121 (\%52.6) Diabetes Mellitus, 118 (\%51.3) Cardiac Disease, 108 (\%46.9) Hyperlipidemia, 58 (\%25.2) Smoking and 46 patients (\%20) Opioid addiction, P $\varangle 0001$ ). Hypertension was statistically significant and increased in hemorrhagic subtype 25 patient (\%70) Intracerebral vs11 patient (\%30) Subarachnoid, $P=0.01$ ). Difference in Cardiac disease $(p \varangle 0.0001)$, Diabetes Mellitus $(p \varangle 0.001)$, Smoking $(p \varangle 0.001)$, Opioid Addiction $(p \varangle 0.04)$ was statistically significant and increased in Intracerebral patients.

Conclusions: mortality rate in our study was low, stroke was more common in female, ischemic stroke was most common stroke type and hypertension especially in hemorrhagic was the most important risk factor for stroke.

Key words: Stroke, ischemic stroke, hemorrhagic stroke, hypertension.

DOI: $10.7575 /$ aiac.abcmed.ca1.12

Published Date: February 2017

Peer-review is under responsibility of the 9th Iranian Stroke Congress.

Published by Australian International Academic Centre, Australia

This published work is open access under the CC BY license.

Available online at www.abcmed.aiac.org.au 